\title{
'Window on the West Indies': the photographic imagination of the Society for the Propagation of the Gospel
}

Darren Newbury

In the mid 1950s, the Society for the Propagation of the Gospel (SPG) sponsored two substantial photographic exhibitions in Britain, on South Africa and the British West Indies, promoting its mission activities and forming the centrepieces for fundraising campaigns. This article takes the latter exhibition - 'Window on the West Indies' - as an opportunity to examine the Society's evolving approach to the medium, and its photographic archival legacy. Departing from an earlier practice of relying primarily on missionaries to supply photographs from the field, and unlike the somewhat serendipitous circumstances of the South Africa exhibition, 'Window on the West Indies' resulted from a professional commission. In addition to raising issues of ownership and control of photographic production and the photographic image, the commission signalled an increasingly ambitious use of the medium to promote the Society's Christian missionary worldview. Yet, I suggest, this very photographic ambition opens the door to alternative readings that escape the limits of the Society's intentions. Beyond its role as mission propaganda, including some highly controlled uses of the photographs within its publicity material, the project can be located in the context of a post-war convergence of international humanist and humanitarian narratives expressed in visual form, and a belief in the capacity of photography as a medium for mutual understanding. Although a Christian future, secured in the act of donation, underpinned the narrative the Society sought to promote through its selective deployment of the photographs, taking a wider view of the collection it is evident that the photographs also speak to a more open, uncertain and imaginative relation to the world depicted. This latter not only draws attention to the specific presence of the photographer but also provides an opening to enable the collection to be refigured for future audiences. 
In late 1954, as it was in the midst of organising a major photographic exhibition on South Africa as part of its South African Emergency Fund campaign, the Society for the Propagation of the Gospel (SPG) conceived an idea for a second exhibition, on the British West Indies, to be shown in the same space - the crypt of St Martin in the Fields, London the following year. It would form a centrepiece of its West Indies appeal. The photographs would be made by Bryan Heseltine, the same photographer who had produced the South Africa exhibition, only this time working on a direct commission. In contrast to the first exhibition, which formed part of the Society's rearguard action in response to the National Party government's closing down of missionary work within the South African education system, the second exhibition was framed as moment of critical opportunity. Despite the immense difficulties confronting its mission in the region at the end of empire, the West Indies appeal projected a vision of the future, if the Church would only rise to the challenge. As the Archbishop of the West Indies put it,

In every place there come times when the local Church finds itself in a position of such urgency and strategic importance that it must call the whole Church to its aid. Such I believe to be the position in the West Indies at the present time. ${ }^{1}$

In this article, I want to do three things. First, to consider the West Indies commission in the context of the SPG's evolving approach to photography. The commission should be understood not simply in a lineage of missionary photography (Geary 1991; Eves 2006) and mission propaganda (Gullestad 2007, 18-23; Pels 1989), but also in the context of international humanist and humanitarian narratives expressed in visual form and a belief in the capacity of photography as a medium for mutual understanding, which came to the fore in the post-war period (Salvatici 2015; Rodogno and David 2015). ${ }^{2}$ The West Indies commission provides a case study at the intersection of these visual discourses. Decolonisation, national independence movements, international anti-racism and ideas about human rights, as well as increasing secularisation at home, presented significant political and 
ideological challenges to Christian imperialism and missionary evangelism. At the same time mass communication media were fostering an increasingly global consciousness. Mission societies had, therefore, to reshape their activities and their message in order to remain relevant in the changing landscape of international development, and to compete with alternative visions of the future circulating globally. Alongside a deeper appreciation of the importance of visual media, there was a shift in the content of missionary publicity, with greater emphasis on common humanity, modernisation and development, in place of religious conversion narratives. These were themes shared with emerging international organisations (Gaitskell 2011; Compton Brouwer 2011) and engendered a common photographic language, as exemplified by the West Indies commission. Second, in order to give substance to the argument, it is necessary to look in detail at the public photographic outcomes of the commission, the illustrated publication Mrs Roberts visits the West Indies, the exhibition Window on the West Indies and a related article placed in Picture Post, examining the visual narratives they construct, and the ways in which the language of photography both enabled and constrained the imagination of present and future relations in the context of impending decolonisation in the British Caribbean. In conclusion, I return to the photographic archive to consider a number of images that complicate or disrupt these public narratives. Although the SPG's embrace of photography was intended to serve a clearly defined agenda, the aesthetic sensibility of the photographer coupled with the inherent contingency of the medium ultimately escaped the limits of their intentions. Away from the more controlled public contexts of selection and display, the photographs speak to a more open, imaginative and at times uncertain relation to the world depicted, drawing attention to the presence of the photographer and his engagement with the places he visited, and at the same time providing an opening to enable the collection to be refigured for future audiences.

\section{Missionary Photography and the Society for the Propagation of the Gospel}

Although there is not space here to develop an extended account, it is clear that missionary photography has a long history; and the fact that missionary photographers were often 
amateur enthusiasts should not be taken to indicate any lack of visual sophistication. As Eves (2006) notes in his study in the Pacific, missionary photography produced its own distinct genres capable of expressing ideas of Christian humanism, as well as more familiar paternalistic narratives. With the notable exception of Marianne Gullestad's (2007) extended study of the visual output of the Norwegian Missionary Society (NMS) in North Cameroon, however, there has been comparatively little attention to missionary photography after the period of high colonialism. It is to the 1950 s that this article turns its attention, a period during which developments in photography as a medium of international communication are taking place simultaneous with the reshaping, and reimagining, of the world order.

Although there are no published studies of earlier SPG photography, it is clear the Society was not new to the medium and doubtless had its share of amateur photographers amongst its missionaries. ${ }^{3}$ In the 1950 s, however, the SPG began to articulate an increasingly sophisticated understanding of the value of photographs to the presentation of its mission work in an era of mass communication. In this respect, it is comparable with the NMS, which between 1953 and 1963 issued a newsletter through its recently formed film office providing 'advice on photography and filmmaking' (Gullestad 2007, 52). An SPG memorandum from August 1951 made what is later described as a 'high-minded effort' to provide detailed photographic instruction to its missionaries overseas. ${ }^{4}$ This call was reiterated regularly, reminding missionaries of the need for photographs. In September 1953, the Oversea Secretary invited submissions, stating that 'the Exhibitions Department is crying out for good photographs. Some are needed for display panels at exhibitions. Others are required for the making of film strips'. A year later he repeated his call: 'The exhibitions and Editorial Departments and the Picture Bureau are anxious to secure good photographs of the Society's work overseas, in all its aspects'. But not just any photographs would do. There was an explicit effort to script this production of visual material. The emphasis was on photographs that showed activity, especially that of mission-field relationships - 'a doctor attending a patient, an evangelist and his audience, a teacher with her pupils' - as well as 'people 
engaged in their work or enjoying some form of recreation' and 'background material illustrating the life and customs of the people'. 'People in rows are not much use', they were told, and neither were 'static groups or empty buildings'. ${ }^{5}$ Photography, as the SPG conceived it, was a medium for the description of active life; and for the depiction, and activation, of (missionary) relationships.

In the mid-1950s, the Society's Picture Bureau developed a practice of loaning photographs, in sets of nine images, to Parishes for a month at a time, which were 'very popular in making Church-goers familiar with the work of the Society throughout the world'. They had also discovered the potential efficacy of individual photographs for inspiring substantial donations. On several occasions, the Oversea Secretary refers to the Korean mission receiving donations of more than $£ 5000$, 'merely by the publication of a single photograph' (of an orphan); and he speculates that in the case of South Africa, dramatic imagery, such as 'a picture of a bull dozer at work in the Western areas of Johannesburg... might be of tremendous value'. ${ }^{6}$ Nevertheless, despite this awareness of their monetary value, it seems likely that, as was the case with the NMS, a majority of its photographs would have been 'taken during the missionaries' leisure time, at their own initiative and cost' (Gullestad 2007, 53), and for the most part mission headquarters would have regarded 'a photograph [as] something they get for free' (Ivar Barane cited in Gullestad 2007, 53). Commissioning an established professional photographer, sending them into the field and mounting a public exhibition comprising in excess of 100 photographs was of quite a different order. Moreover, it suggests a substantial investment in the capacity of the medium, not simply as a means of documenting their work or evidencing the problems of the present, but as a medium through which it was possible to inspire an imagined future; not simply illustrative of missionary work, but a space within which to foster a missionary imagination amongst a wider British public. $^{7}$ 
In many ways, the public exhibition format was a logical next step for the SPG's use of photography, if a somewhat large one; at the same time, however, it brought them into the ambit of an international photographic discourse that sought to use the medium to project ideas of universal humanity in the post-war period. In her study of the Australian colonial context, Jane Lydon has searched the photographic archive for the 'schemes of humanity, justice and progress' that shaped the visual depiction of Aboriginal peoples (2016, xiii), tracing threads and identifying 'moments of compassion with the potential for change' (xiv) from the mid-nineteenth century onwards, and culminating in the UNESCO Human Rights (1949) exhibition that promoted the Universal Declaration of Human Rights as it toured internationally. The SPG exhibition represents one small part of the story as it continued in the immediate aftermath of that moment in a worldwide context. The decade or so following the end of the Second World War saw a universalist view of humanity and human rights displace Christian universalism (Jensen 2016, 22) and the 'classical standard of civilisation' (Liu 2014, 396), which had accompanied colonialism and shaped its ideology, as measures for articulating human progress within international discourse. ${ }^{8}$ Photography became a preeminent medium giving visual expression to this idea of 'a common transnational humanity' (Rodogno and David 2015, 231). A few years after the UNESCO exhibition, the Museum of Modern Art (MOMA) in New York mounted The Family of Man (1955), curated by Edward Steichen, the much-debated pinnacle of photographic expression of universal humanism. And during this period many other smaller exhibitions and projects can be seen to exist within its ambit. In Bryan Heseltine, the SPG had selected a photographer who although not strictly a member of that cadre of photographers most closely associated with a humanist vision in the post-war years had nevertheless imbibed this international language of photographic humanism during the periods he spent in Europe and through his participation in international photographic networks. Indeed, four of his South African photographs were included in Edward Steichen's Post-War European Photography exhibition at MOMA, New York, which served as a precursor to The Family of Man. ${ }^{9}$ The point here, however, is not 
simply that the new paradigm superseded the old, but rather that, away from the spotlight of world photography exhibitions, the transition was uneven and at times contradictory.

The language and imagery of universal humanism and human rights would not displace long established missionary narratives in their entirety, but they certainly had an influence on the forms they took, and vice versa. As Lydon points out, one can find many examples in the photographic archive that speak to the 'acknowledgement of another's humanity' (2016, 2-3), and missionary narratives often deployed photography in support of the belief that no people was so irredeemably other as to not hold 'Christian and civilized potential' (9); in contrast to forms of colonial imagery that implied an unbridgeable difference, where they did not exclude colonial subjects from the category of the human altogether. Compared to the period of high colonialism, however, during the post-war years photography served the presentation of conversion narratives expressed less directly in religious terms than in a capacity for modernisation and development. As Rodogno and David point out, international agencies such as the World Health Organisation drew inspiration from 'before and after' conversion narratives as they shaped their own visual rhetoric, which was 'not always clearly distinguishable from civilizing mission narratives' $(2015,240)$. Equally, as former colonial territories gained independence and new international agencies emerged to work alongside or supplant mission societies there was a discernible visual as well as ideological convergence. As there was traffic in personnel between mission societies and international humanitarian organisations (Gaitskell 2011, 257), so there was traffic in images. In this sense, the SPG's photographic imagination was no longer entirely its own, as will become clear through a discussion of the 1956 West Indies exhibition and its archival presence.

\section{Photography and the West Indies Appeal}

The West Indies commission can be viewed as a highpoint in the SPG's use of photography.

The initial engagement with Heseltine and the discovery of his substantial body of South African photographs was largely a matter of chance (Newbury 2013, 32). Nevertheless, 
opportunistic as it may have been, it clearly chimed with the Society's emerging sense of the importance of the medium. In no time at all, they had planned the South African exhibition and, almost simultaneously, proposed the West Indies commission. It was not simply about documenting the work of the Church in the region, but more ambitiously aimed to describe the world in which they operated, at the same time as endowing the medium with the capacity to inspire in the viewer an imaginative, and material, investment in its future.

The West Indies Appeal was framed as critical moment for the SPG's mission in a region where they had been present since the beginning of the eighteenth century. Notwithstanding their chequered history in relation to colonialism and slavery, the Society saw in the emerging post-war world order an opportunity to renew their mission and win, or lose, the people of the West Indies for Christ. ${ }^{10}$ The launch of the appeal was expressed in dramatic terms, acknowledging the challenge posed to the Church by decolonisation: 'Far reaching political and economic changes are hastening the advancement of the Caribbean territories towards the maturity of full nationhood and the next ten years will decide whether we shall have a Christian nation or a nation founded upon soulless materialism'. But it was not only 'soulless materialism' that the Society was seeking to contest; other religions and political movements that proposed alternative visions of the future were also within their sights. As Pels notes, from the 1940s communism and anti-colonial nationalisms increasingly replaced so-called primitive religions or 'savagery' as the alternative poles of authority that missionaries sought to confront (Pels 1989, 40). ${ }^{11}$ The important point here, however, is that the Society's engagement with Heseltine inserted photography into this ideological contest for the future. But in order to exploit its full potential they had also to concede something to the openness and potentiality of the medium as a space of transnational, and indeed historical, imagination, and individual aesthetic vision.

The West Indies photographic tour was planned in December 1954 just as the Secretary of the Society, Bishop Basil Roberts was preparing to lead a delegation on a fact-finding trip to the 
region. Heseltine followed on afterwards, his photographs providing a visual parallel to the Secretary's report. Given the imploring tone of the Oversea Secretary's requests for photographs, one can imagine that Heseltine appeared heaven sent, fulfilling a desire for a more sophisticated and complete form of photography, inspired no doubt by the international prominence of the medium, which the overseas missionaries themselves were unable to deliver.

Records of correspondence give an insight into the thinking about photography at SPG at the time. In January 1955, the Home Secretary wrote to the Archbishop of West Indies emphasising the financial rewards the proposed photographic project may reap, and seeking to allay any fears the medium, or indeed profession, evoked. Commissioning a professional photographer was not common practice, as is evident from the perceived need to discuss Heseltine's personal convictions, and the admission that 'possibly he was not much of a Churchman'. Nevertheless, his character and capacity for empathy, as well as the mechanisms of control the Society was able to exert over the resulting photographs, were offered as reassurance. Heseltine was described as a 'charming fellow' who 'knows how to behave'; and although the depth of any religious faith he may hold was unknown, his feeling for the 'colour problem' in South Africa was regarded positively for the Society's ambitions in the British Caribbean. Furthermore, he represented a certain kind of photography: 'his ambition in life is to be a serious documentary photographer. He is not the sort of chap who deals in slick journalese cum night club photography'. The former phrase hints at recognition of the photographic aspirations that coalesced around the illustrated press, Magnum Photos and international organisations such as UNESCO in the immediate post-war period. The letter went on to describe the ambitions for the project:

What we want from Heseltine is a set of photographs which through human studies, will portray the varying types of people amongst whom the Church is working and those she is trying to reach. People at home; people at work; 
conditions of life and work and play in varying surroundings of city, township, and country. Living conditions good and bad. ${ }^{12}$

Aside from its religious and moral framing, what was being described here echoed precisely the content of The Family of Man exhibition, and despite vast differences in scale it is clear that the photographic imagination expressed in the SPG West Indies project shared common ground with the transnational humanism of Steichen's exhibition.

It is evident nonetheless that the SPG wanted ownership and control of the project and, congenial as the photographer's character may have been, they were not prepared to leave anything to chance. In a separate letter, the Home Secretary provided categorical reassurance to the Archbishop of the West Indies, who presumably had expressed some concerns about what Heseltine's camera might reveal:

You need not have any fears about giving him full rein, because every single picture that he takes is the property of SPG under the written contract that we have with him, and it will be the Society, as owner of the copyright who decides whether or not a picture is to be retained and used, or scrapped... he may come back with certain pictures which for one reason or another we would not wish to use, and such pictures when they are developed we shall not hesitate to destroy. ${ }^{13}$

The photographic tour departed on 10 February 1955 with an itinerary that included Trinidad, British Guiana, Antigua and Jamaica, returning at the beginning of April. Heseltine kept only a limited written account of his trip, with brief notes on his schedule, subjects and lighting conditions recorded in a pocket diary. Whilst in one sense frustrating, this says something about his and the Society's understandings of photography, reinforcing the idea that this was not a documentary project in a strict sense of that term, but rather that photography was invested with grander ambitions. ${ }^{14}$ Further evidence on this point is found in a letter the 
photographer wrote to the SPG Home Secretary, a little over a week into his trip, wherein a notion of human, social and cultural variety is emphasised repeatedly: 'races, industries, and variations of scenery' (Trinidad); 'new settings, races, customs, etc.' (British Guiana); 'types, settings, folklore, etc.' (Jamaica). And it is clear that the desire to get 'good photographic shots' existed in tension with the demands of documenting Church activities - 'I see no point in photographing every church school, every christening, every confirmation, etc: unless they are significantly different' ${ }^{15}$

\section{Mrs Roberts visits the West Indies}

The first use of the West Indies photographs came shortly after Heseltine had returned. Published in the second half of 1955, Mrs Roberts visits the West Indies (Figure 1) was a small book providing a narrative account of the Society's fact-finding trip from the perspective of one of its participants, Dorothy Roberts, Central President of the Mothers' Union, and wife of the SPG Secretary Basil Roberts. It took the form of a contemporaneous report of the visit. The writing is a mix of mission narrative, in the style of a jolly travelogue, first hand accounts of the people and conditions encountered, and sociological description. The book reproduced 16 photographs, inserted on separate pages as groups of between two and six images and on the cover.

This small publication is the most constrained of the sites of reading discussed here, nevertheless, it is interesting to note the division of labour between text and images. Where the text includes discussion of issues such as the legacy of slavery, West Indian nationalism, the British government's intervention in British Guiana to remove the left wing People's Progressive Party, described as the 'remov[al] of an alien force' $(1955,56)$, and the ongoing conflict between communists and the Church, none of these are referenced in the selected photographs, which are almost exclusively used to present a positive image of progress. ${ }^{16}$ Nor I suspect would the reader discern this content from either the front or back cover. The latter reproduced the image of the child that would be used for the exhibition poster. The 
former presented an image of a palm beach devoid of people, a choice that seems quite unusual given the stress elsewhere on active life, but which one might assume was intended to draw its British readers in with an appeal to a stereotype of the Caribbean as an idyllic island destination. It may also be taken as an illustration of a comment by Dewi Morgan, the Society's Editorial and Press Secretary, in his foreword: 'As far as nature is concerned there almost every prospect pleases. But man has made much of it vile' (Roberts 1955, 9). Taken as a whole the selection of photographs used in the book fulfilled the prescription for mission photography that the Society presented to its missionaries. Half of the photographs either present directly or allude to paternalistic relations of one kind or another - a priest ministering to a sick woman, another talking to a woman working in a field, children and young men being tutored, a child being baptised - with simple captions expressive of these relations: 'Sick and Ye Visited Me'; 'Go into the Highways'; 'Day and Sunday School'; 'Discussion with the Tutor'; 'Christ's Faithful Soldier'. There are only three photographs that do not project the promise of the Church for a better future; these address social problems discussed in the text. One refers to the problem of chronic overcrowding, with a dignified group portrait of a large family on the stoop of their house. The seriousness of the subject is rather undermined, however, by its juxtaposition with the opening chapter, entitled 'Farewell London: To Sunshine via Iceland'. Another pair of images is addressed to the question of women's work. Unsurprisingly, given its author's role in the Mothers' Union, issues of illegitimacy, attitudes to marriage and the idea of 'the Christian family as the healthy unit of society' $(1955,28)$ are strong themes.

The closing photograph of the book presents a beautiful young girl engaging with the camera, entitled 'Confidence in the Future' (Figure 2). I will return to this photograph later, but for the moment it is sufficient to note the way in which the image activates a missionary relation: the girl symbolises the future in which the viewer is invited to make an imaginative investment, the corollary of which is support for the action of the Church. Although the photographs in Mrs Roberts visits the West Indies enhanced this particular missionary 
narrative, it is clear that such a small and highly constrained selection did not do justice to the ambition of the photographic project, nor exhaust the rich pool of photographs that resulted from Heseltine's tour. For this one needs to view first the public exhibition, 'Window on the West Indies', and then the photographic archive.

\section{Window on the West Indies and Islands of Hardship}

'Window on the West Indies' opened at St Martin in the Fields, London, on 8 June 1956. It is striking to learn that Alan Lennox Boyd, Secretary of State for the Colonies, was invited to open the exhibition, demonstrating the close relationship the SPG had with the British political establishment, and a clear indication that the Society continued to view its mission work in the West Indies within a colonial framework. Despite overseeing the early period of decolonisation, Lennox Boyd took a 'Churchillean view on empire' and the capacity of colonial peoples for self-government, as well as turning a blind eye to human rights abuses in Kenya during the Mau Mau uprising (Elkins 2005, 139-40). ${ }^{17}$ The choice of opening speaker cannot be held to define the meaning of the exhibition; nevertheless, it is instructive for understanding the interpretive limits of an historical reading, at least from the perspective of its sponsors.

If Mrs Roberts visits the West Indies was a more or less predictable piece of mission propaganda and made rather limited use of photography, an exhibition of necessity had to embrace a more ambitious vision. The final selection comprised 149 photographs organised in thematic sections. And in a repeat of their media strategy for the South Africa exhibition, the SPG used their connections to place an illustrated article in Picture Post coinciding with the show - 'Islands of Hardship' by Rev. Chad Varah (16 June 1956). It is clear from the archival record that the final shape of the exhibition was the result of a negotiation between the photographer, with the assistance of close friend and colleague John Parminter, and the SPG, marrying the former's photographic ambitions with a narrative framing that accorded with latter's overarching view of the region. The exhibition design was in the hands of 
Heseltine and Parminter, and reflected ideas of the time around the communicative and pedagogic capacity of photography. The main sections of the exhibition were accompanied by very minimal text. Enlarged and mounted on the wall in thematic groupings, without frames or captions, the photographs were assumed to communicate with an immediacy and emotional directness. The draft scripting notes for the exhibition suggest there was some debate around the placement of text panels, and a sense that for the SPG the ambiguity of the image was a source of mild anxiety. In relation to the opening section it was noted that, 'According to these arrangements people will see the first $8 \mathrm{ft}$. of the exhibition before they read a word. The first bit of text appears to be too unobtrusive'; and, referring to the final section, 'we are at liberty to caption to any desired degree'. ${ }^{18}$ The final layout notes, alongside photographs of the installation, suggest that the photographer managed to retain a fair degree of control. Although most of the content was organised according to clearly defined sections, the exhibition included a significant middle part where the sequencing was not limited to a single theme, and even allowed the inclusion of photographs of local flora, a photographic subject at which Heseltine excelled.

If Heseltine's approach represented a more confident embrace of the communicative potential and autonomy of the photographic image, nevertheless the narrative framing established a very clear political worldview; no doubt one which Heseltine shared in part. Beyond the SPG's use of photography to convey simpler mission narratives, the exhibition represented a more all-embracing view of the relation between mission, empire and development. At the same time, without the depth of Heseltine's photographic understanding and his aspiration to capture the diversity of settings, housing, customs and people, rather than simply document the work of the Church, an exhibition on this scale would not have been possible.

For its British audience, the SPG intended the exhibition as a lesson in the responsibilities of empire. ${ }^{19}$ The imperial context was made absolutely clear in the group of photographs around the main entrance, which included an image of a plaque from Port Royal, Jamaica, that read 
'In this place dwelt Horatio Nelson', and a view from a fortified position overlooking Nelson's Harbour, Antigua, accompanied by a short text panel, which included the following: 'From Drake to World War II West Indian Islands have been coveted naval bases for European sea powers. Much British history has been decided in the West Indies'. Juxtaposed to this opening was a cluster of portraits, referred to simply as 'heads', which immediately peopled this vision of empire. Yet, Heseltine's skill as a portraitist allowed space for these subjects to present themselves on terms not entirely subservient to the colonial context; for example, there is something about the way in which the female Jamaican banana plantation worker faces the camera with half-finished cigar in mouth that escapes any overarching narrative.

Within its imperial and Christian framing, the exhibition contrasted current hardship with a vision of the future, a future of economic development and modernisation. Industry was a key theme, with sections specifically on oil, bauxite, sugar and bananas, accompanied by a text panel stating that 'The West Indies calls out for further industrial development or it cannot support its peoples'. Several photographs showed the labour intensive work associated with sugar and banana plantations, as well as more basic forms of agriculture. At the same time, however, the exhibition included images of modern efficient forms of machine work. The sugar industry was represented by a photograph inside a factory showing workers operating the 'spin driers' that filtered the sugar, as well as men and women cutting cane by hand and loading barges. The visually striking steel structure of Trinidad's oil refinery presented a powerful image of modernity; and although not included in the final selection, one photograph taken at the refinery demonstrates how the photographer staged small scenes for the camera dramatising the shift from physical labour to the operation of complex technology (Figure 3). The exhibition also showcased developments in housing, education and healthcare. There were photographs of new townships on the outskirts of Georgetown, British Guiana, to contrast with overcrowded housing shown elsewhere, the latter described as 'sordid conditions where lack of privacy gives little encouragement to morality'. The 
section on hospitals included a photograph of a 'huge' modern hospital in San Fernando, Trinidad, and another of an English physiotherapist bandaging the leg of a Jamaican man in a modern hospital setting (Figure 4), a gesture of care that evokes humanitarian as well as development narratives (Rodogno and David 2015, 240). In the section on education the selection was, unsurprisingly, biased towards photographs of Church schools and the theological college in Jamaica; nevertheless, the main visual contrast was between small outdoor classrooms, signifying a lack of resources, and modern and well-equipped schools, such as the new Technical School in British Guiana.

To accompany the visual narrative of development, the exhibition included substantial sections on culture: 'Song and Dance' and 'Cricket'. The latter probably needs no explanation for an exhibition that sought to foster a sense of imagined community, albeit within the hierarchies of empire, between a British audience at home and British subjects in the Caribbean; a point underscored by the inclusion of a photograph of Canon King congratulating a Jamaican player for scoring a century against the Australians in Kingston. The section on music and dance, however, had to deal with difference rather than a shared sporting enthusiasm, and it is instructive to see how this was negotiated. The emphasis here was on culture as tradition and as carnival, both of which framed difference in terms that contained any challenge it might present to the modernising project represented in other sections of the exhibition. Difference is rendered as human variety. The photographs included a group of images illustrating a 'traditional' country dance accompanied by hollow bamboo sticks, and a further group showing a 'progressive modern dance group in Trinidad... trying to bring back to life the traditional dances of their country'. There were also two photographs taken during the San Fernando Carnival, including one of masks hung across the street (Figure 5). Although the latter might be read in opposition to Christianity and empire, it is framed by the idea of carnival as tradition rather than representing a living value system that might prove more challenging. There is little sense here, as there was in the text of $\mathrm{Mrs}$ Roberts visits the West Indies, of the Church having 'to cope with all sorts of novelty 
religions, "religions that never knew Bethlehem" as one missionary called them' (Roberts 1955, 57). Significantly, this photograph comes at the start of the sequence, which goes on to show photographs such as one of a smartly dressed schoolboy playing the flute, implying a certain cultural hierarchy in spite of the apparent relativism and respect for non-European traditions. This section also included several photographs of steel bands, an image of that would have an enduring place in the representation of Caribbean culture in the multicultural Britain that was beginning to take shape during this period.

The photographic language of modernisation and development in concert with culture as heritage and tradition that the exhibition articulated was not unique to the photographer or to the SPG. Rather, this was part of a visual language shared by many international actors during the post-war period. Its Christian message notwithstanding, the exhibition had much in common with the cultural projections of the United Nations and UNESCO, organisations which, as Glenda Sluga points out, tended to imagine postcolonial subjects, 'as efficient modern workers, educated to the manipulation of machines and management of the mass agriculture and industry that was their future'. And whose 'consequently lost cultures' were 'left to UNESCO, as part of its commitment to cultural diversity through the deployment of anthropologists and the creation of museums' (Sluga 2010, 414). ${ }^{20}$ Absent from this picture, and from the exhibition, was any sense of the subjects as political actors on their own behalf.

The article that the SPG placed in Picture Post to coincide with the exhibition - 'Islands of Hardship' - echoed the key themes of the exhibition in a more distilled form. The message emphasised the responsibility of the British public to assist these loyal subjects of empire in order that their current hardship might be assuaged and the path set for their future development. Where the article did differ slightly from the exhibition was in its acknowledgement of a political context beyond empire and the Church. Doubtless reflecting the concerns of its wider readership, the magazine interpreted the photographs in the context of post-war migration from the Caribbean to Britain. In a deeply offensive metaphor 
reminiscent of many subsequent debates surrounding immigration, the article pointed out that as a result of poverty in the Caribbean, 'some of the mixture slops over into our sacred welfare state'. The now familiar subtext to this narrative of responsibility was that assistance there would keep them from coming here. More positively perhaps, the article acknowledged both the historical dimension - 'Our forefathers created the problem of the West Indies' - and the international context of British attitudes towards the Caribbean - 'It's easy to condemn apartheid in South Africa and racial discrimination in Alabama. The West Indies challenge us to prove our greater enlightenment'. Though of course here too political agency and independence on the part of colonial subjects could only be imagined as a source of anxiety, where it was acknowledged at all.

The SPG had a relatively well-developed understanding of the politics of visual representation, and were quite prepared, as they put it, 'to use or suppress' specific images accordingly. ${ }^{21}$ This is evident in the publications and exhibition even if, as I have argued, they were participating in a shared visual language that was not theirs alone. In taking on a photographic project of this scale and commissioning an independent photographer, however, they were also working at the edge of their capacity to direct the process, as is clear in their dependence on the photographer's visual imagination and his appreciation of modern exhibition design. Furthermore, they were certainly not set up to manage the photographs over the longer term, even if they did retain them as per the contract. And it is to the photographic archive as a largely unmanaged and unedited space that I now want to turn.

\section{Traces of other pasts and alternative futures}

To this point I have focused attention on the public outputs and the ways in which the photographs were narratively framed to present, more or less successfully, the message intended by the SPG. In this sense, the SPG appears as the putative curator of the work, and their voice has been given interpretive priority. In this final section, I want instead to read the photographs from the archive, in a raw state, stripped of their textual and contextual 
framing. ${ }^{22}$ Doing so, I suggest, displaces the assumed authority of the SPG and reopens the photographic collection to new interpretations. This is not to assert the polysemic nature of the image, which places too little demand on the act of looking at photographs, but rather making an interpretive effort to reconnect the potential for future readings to the moment of their making, 'taking photography seriously as an encounter' (Azoulay 2013, 21) in the act of interpretation. It is to reinsert the presence of the photographer and the photographed, which for the SPG appeared conversely as risks to be mitigated.

In his study of Dutch missionary photography, Pels makes the point that, in observing the transition of photographs from field to publication, 'it should not be forgotten that the photographers were not the publishers of the photographs' $(1989,38)$. In other words, the interests and intentions that attended the making of the photographs were likely different from those invested in their subsequent publication. This is a direction that can be reversed in the act of interpretation, and it is in the photographic archive that this work can begin. For Pels, this move enables a reading of the photographs outside of a simple missionary 'tale of progress and opposition to progress'; rather, he argues, the photographs 'present others without visible reference to what should, or should not, be the goal of mission work' (1989, 35). This is not simply about recovering private meanings (Geary 1991) in the archive but, rather, recognising in the photograph a moment of uncertainty and possibility.

Despite their detailed instructions, the stipulations of a contract and his being accompanied during the trip, the SPG could not constrain Heseltine's restless visual curiosity and his distinctive aesthetic response to the environment in which he was working. Heseltine's photographic imagination is discernible to a degree in the exhibition; however, it is in the archive, unhindered by the publicity requirements of the SPG, that it is more fully present. Moreover, it is in the archive that aspects of the historical setting in which the photographs were made become visible in ways that they were not in any of the public presentations. I 
want here, therefore, to consider a number of photographs that were not selected for publication or exhibition, and to reposition some of those that were.

Removing the photographs from the context of a missionary or development narrative has the effect of drawing attention to the photographer's way of engaging with what he saw. And it is clear that Heseltine's own photographic inclinations were towards an intensely aesthetic response to the world around him. Unlike his sponsor he was not vested in the creation of social narratives through photography, missionary or otherwise. Viewed in isolation, as images, photographs in the collection that do not directly illustrate the SPG's vision of mission work convey little of the hierarchies of value that their later contextualisation would seek to foist upon them. The painted masks Heseltine photographed strung on a wire across the street, visual signifiers of non-Christian belief systems or carnivalesque satire, are treated with a formal and aesthetic equivalence to the double-breasted jacket hanging in the open air (Figure 6). Viewed together the images are more strongly suggestive of a surrealist sensibility than an evangelical message. Equally, it is evident that the photographer's interest in the large advertising billboards placed in the landscape was absent of any moral overtones. A photograph of a 'Carib' (beer) billboard in Trinidad, for example, delights in the visual play of the graphic image and its presence in the environment (Figure 7); and likewise the full frame image of a comical advertisement for Raleigh bicycles, showing a cyclist being chased by a lion, celebrates its visual humour. ${ }^{23}$ Even the photographs of the Trinidadian oil refinery, which in the context of the exhibition illustrated a promising future of industrial modernisation, in the archive seem more drawn to its compelling visual strangeness (Figure 8). The point is not that there is a coherent alternative vision of the British Caribbean on offer here, but rather than the photographer is pursuing a set of aesthetic interests that are not constrained by the missionary framing of the project, and which might be argued to outlast the narrative it sought to impose. To take another example, amongst the contact sheets one finds an ethnographic style sequence of an indigenous inhabitant of British Guiana fishing with a bow and arrow, taken on what appears to be a trip up river into the interior of the 
country. The fisherman and his technique appear to have interested the photographer rather more than his ostensible reason for being there - the visit of the Anglican priest he was accompanying.

An archival reading of the photographs also enables those aspects of the historical moment not visible in the SPG publication and exhibition to be brought into view. As noted above, the public presentations of the photographs shaped a narrative within which the agency of those depicted was largely absent. The people of the Caribbean shown in the photographs selected were primarily, prospective or actual, recipients of the care and ministry of the Church or beneficiaries of development. Where the subjects were shown as agents it is as converts to a modernising, Christian world, as doctors, police officers, students, teachers or pastors. Political opposition, as there certainly was in the British West Indies at the time, was not made visible through the photographs, even where it featured in the accompanying textual commentary, as in Dorothy Roberts' reference to 'well trained bands of young Communists' $(1955,57)$ in British Guiana. One might assume that there were no such photographs to illustrate the point. Yet, a small number of photographs in the archive refute this assessment, suggesting instead that political agency and opposition were deemed unsuitable for visual representation by the SPG. What is striking about the photographs that might have been used to represent this aspect, however, is their tentative and uncertain quality. In British Guiana, Heseltine photographed the office of the People's Progressive Party, whose success in elections less than 2 years before had led to intervention by the British government, removing them from power (Figure 9). Yet, there is palpable hesitation here, and the photographer, who typically got close to his subjects, remains at a remove. Taken from across the street, the photograph provides evidence of apprehension in the moment of photographing, reinforced within the image by the ambiguity of the word 'THUNDER' painted in capital letters on the building front. And, on the contact sheet, the marking in pen of a circled dot, suggesting its selection for printing, is immediately followed by a question mark. Other images are more ambiguous, hinting at another reality through signifiers glimpsed as the photographer moved 
through the environment. In Jamaica, he recorded a crude graffiti image on the wall of a house: a man holds out in front of him a long whip, next to the painted words 'THE BLACK WHIP'. On the same roll of film, another photograph shows two men working outdoors, positioned against an expanse of white wall on which, in the centre of the image, are the words 'WE WANT WORK'. In Trinidad, Heseltine photographed what might have been a small carnival procession, but the carrying of a flag at the rear hints at a more political expression. Again, unlike his usual proximity to his subjects, this image is taken from a slight distance and elevation, signifying perhaps the photographer's own uncertainty about what he was observing. None of these photographs appeared in the exhibition or are elsewhere commented upon. Even photographs of a pro-British political demonstration on the streets of Trinidad - the marchers carry a banner on which the words 'Mau Mau Terrorists in Kenya' are clearly legible - remained in the archive outside the realm of public visibility. It is impossible to know what Heseltine was thinking when he made these photographs, but at the very least they represent a tentative photographic engagement with a dimension of life in the British West Indies to which at that moment the SPG did not see fit to grant visual representation. These are moments when the environment in which Heseltine was photographing began to impress itself on his visual sensibility in spite of the script the commission invited him to follow.

Where the SPG were clear in what they saw and wanted to share this vision with a British public, these unused images speak to the photographer's uncertainty about what was before him and how he might make sense of it photographically. This is apparent in another intriguing image taken in Antigua (Figure 10). The photographer's view of the scene was partially obscured by a low wall and metal fencing, indicative one suspects of a desire on his part to remain unnoticed. The photograph records a street corner a few moments after two figures have passed each other; the man on the left in light shirt and hat appearing to move in a relaxed and confident manner contrasts with the dark-clothed man on the right slightly hunched over pushing a barrow, projecting a sense of slow, heavy, burdened movement. 
Compositionally the photograph is not entirely successful, but nevertheless it is hard not to read it as the photographer searching after a metaphor for the contradictions of world he saw on his visit to the region.

Finally, the archive contains traces of moments when the photographer's visual exploration of this unfamiliar environment collides with the refusal of those who came before his camera to accede to his gaze. Whilst a majority of those photographed appear to have been willing or at least compliant subjects, it is evident that not all were such eager sitters. In what is a striking comparison, I want to return to an image that appears to have been highly valued by the SPG; it appears in the book publication, the Picture Post article and the exhibition, forming the closing image in the two published outputs. Entitled 'Confidence in the Future' in the book (Figure 2), it shows a light-skinned girl seated selling fruit at an open market in British Guiana. She has turned towards the camera and smiles engagingly. Juxtaposing this photograph with one made a few frames later, but which did not appear in either publication or exhibition, throws into stark relief the process of image selection (Figure 11). In this photograph a darker skinned girl looks directly into the lens; rather than being seduced by the camera, she has adopted a quizzical if not outright resistant stance towards the photographer whilst she is engaged in her work. The awkwardness and confrontational nature of this encounter challenges the idea of reciprocity and mutual understanding often claimed by humanist photography, and has no place in a missionary narrative of modernisation and development.

Pursuing this line of thought, I want to end the article with possibly the most extraordinary photograph in the collection, made on the edge of a bay in Antigua, in which a young woman holds up a battered metal can to obscure her face from the gaze of the camera (Figure 12). Confronted by this image in the archive, one is returned to the moment of encounter on which all photographs depend, its small act of refusal a hard knot of meaning set against the smooth grain of official narratives. 'Window on the West Indies' was an exhibition formed within a 
Christian vision of empire engaged in the project of imagining a postcolonial future. Yet, if it invited the viewer into an imagined community with its subjects it did so on profoundly unequal terms. What Stimson identifies as the search for a new 'affect of belonging' in the photographic projects of this period, a 'desire to experience the other anew' $(2006,7-8)$, can here never quite escape an affect of empire and responsibility. In this moment, for the SPG, there is little sense of the 'post-colonial soul-searching' (Compton Brouwer 2011, 266) that came to occupy mission societies in future decades. The photographic archive, however, remains a place of possibility open to new audiences to activate these unseen images, to recall other pasts in the service of better futures.

\section{References}

Azoulay, A. 2013. "The Family of Man: A Visual Universal Declaration of Human Rights.” In The Human Snapshot, edited by T. Keenan and T. Zolgahdr, 19-48. Berlin: Sternberg Press.

Burke, T. 2002. “'Our mosquitoes are not so big’: Images and Modernity in Zimbabwe.” In Images and Empires: Visuality in Colonial and Postcolonial Africa, edited by P. S. Landau and D. D. Kaspin, 41-55. Berkeley: University of California Press.

Compton Brouwer, R. 2011. "When Missions became Development: Ironies of 'NGOization' in the Mainstream Canadian Churches in the 1960s." In Protestant Missions and Local Encounters in the Nineteenth and Twentieth Centuries: Unto the Ends of the World, edited by H. Nielssen, I. M. Okkenhaug and K. H. Skeie, 259-91. Leiden: Brill.

Elkins, C. 2005. Imperial Reckoning: The Untold Story of Britain's Gulag in Kenya. New York: Henry Holt and Company.

Eves, R. 2006. “'Black and White, A Significant Contrast': Race, Humanism and Missionary Photography in the Pacific.” Ethnic and Racial Studies 29(4): 725-748.

Gaitskell, D. 2011. "Mission by Other Means? Dora Earthy and the Save the Children Fund in the 1930s." In Protestant Missions and Local Encounters in the Nineteenth and 
Twentieth Centuries: Unto the Ends of the World, edited by Hilde Nielssen, I. M.

Okkenhaug and K. H. Skeie, 233-58. Leiden: Brill.

Geary, C. M. 1991. "Missionary Photography: Private and Public Readings.” African Arts 24(4): 48-59, 98-100.

Gullestad, M. 2007. Picturing Pity. Pitfalls and Pleasures in Cross-Cultural Communication: Image and Word in a North Cameroon Mission. New York: Berghahn Books.

Jensen, S.L.B. 2016. The Making of International Human Rights: The 1960s, Decolonization and the Reconstruction of Global Values. New York: Cambridge University Press.

Liu, L.H. 2014. "Shadows of Universalism: The Untold Story of Human Rights around 1948." Critical Inquiry 40: 385-417.

Lydon, J. 2016. Photography, Humanitarianism, Empire. London: Bloomsbury.

Newbury, D. 2013. People Apart: 1950s Cape Town Revisited. Photographs by Bryan Heseltine. London: Black Dog Publishing.

Pels, P. 1989. “Africa Christo! The Use of Photographs in Dutch Catholic Mission Propaganda, 1946-1960." Critique of Anthropology 9(1): 33-47.

Roberts, D. 1955. Mrs Roberts visits the West Indies. London: The Society for the Propagation of the Gospel in Foreign Parts.

Rodogno, D. and T. David. 2015. “All the World Loves a Picture: The World Health Organization's Visual Politics, 1948-1973.” In Humanitarian Photography: A History edited by H. Fehrenbach and D. Rodogno, 223-48. New York: Cambridge University Press.

Salvatici, S. 2015. "Sights of Benevolence: UNRRA’s Recipients Portrayed.” In Humanitarian Photography: A History edited by H. Fehrenbach and D. Rodogno, 20022. New York: Cambridge University Press.

Sluga, G. 2010. "UNESCO and the (One) World of Julian Huxley." Journal of World History 21(3): 393-418.

Stimson, B. 2006. The Pivot of the World: Photography and its Nation. Cambridge, MA: MIT Press. 
Twomey, C. 2015. "Framing Atrocity: Photography and Humanitarianism." In Humanitarian Photography: A History edited by H. Fehrenbach and D. Rodogno, 47-63. New York: Cambridge University Press.

\section{Notes}

1 'West Indies Appeal', From the Archbishop of the West Indies, Autumn 1955. Collection of the author.

${ }^{2}$ The post-war moment considered here represents a specific development in a longer history of the relationship between photography and humanitarianism. Twomey (2015), for example, dates the emergence of a specifically humanitarian photography to the late nineteenth century, and the coverage of Ottoman atrocities in Bulgaria and the contemporaneous Indian famine.

${ }^{3}$ As early as the 1850s, the Anglican Church in Australia was actively commissioning photographic portraits of Indigenous subjects, presented in upper-class western dress to signal their newly achieved civilised status and provide visual evidence of 'conversion narratives' (Lydon 2016, 26-9).

${ }^{4}$ I have yet to locate a copy of the August 1951 memorandum. Reference to it is made in a later memorandum: 'To all our Missionaries', September 1953, A.E.A Sulston (Oversea Secretary). AB1289, Historical Papers, William Cullen Library, University of the Witwatersrand, Johannesburg (hereafter Cullen Library).

5 ‘To all our Missionaries', September 1953; ‘To all our Missionaries', September 1954, A.E.A Sulston (Oversea Secretary). AB1289, Cullen Library. The Society also advocated the collection of curios, providing a material culture dimension to the displays it was able to mount, and the use of flannelgraphs for forms of visual storytelling.

${ }^{6}$ Letter from Oversea Secretary, 14 January 1955, Papers of the United Society for the Propagation of the Gospel, Bodleian Library of Commonwealth and African Studies (hereafter, Bodleian USPG papers).

${ }^{7}$ As an indication of the value they accorded the project, the SPG bought a new Rolleiflex camera and Tessar lens for Heseltine to use; and the total cost for the project of $£ 658.11 .1$ 'wiped out' the credit balance of the Visual Aids reserve budget created in 1948. File TF3716, Archives of the United Society for the Propagation of the Gospel, London (hereafter, USPG archives).

${ }^{8}$ Although beyond the scope of this paper, it has to be acknowledged that this was a short-lived moment, and that the dominant forms decolonisation took largely supplanted or disregarded the discourse of human rights, making its photographic expression seem in retrospect either hopelessly naïve or complicit with the maintenance of Western dominance. See Stimson (2006) for an argument on the brevity of this photographic moment.

${ }^{9}$ Postwar European Photography, Museum of Modern Art, New York, 26 May - 23 August 1953.

10 'In the West Indian islands the Society has more usually been regarded as a reactionary force, owning slaves openly and in league with the planters'. West Indies material in the archives of the 
USPG, 1710-1950. Available online at:

<www.britishonlinearchives.co.uk/collection.php?cid=9781851172276> [Accessed 19 December 2016].

${ }^{11}$ Discussing Dutch missionary work in Africa, Pels notes that, "from the late 1940s onwards... some missionaries started to warn their colleagues that the struggle against the "carnal lusts of the uncivilized or half-civilized" was being replaced by the fight against "the satanic lust of power of godless communism and exaggerated irrational nationalism"' $(1989,40)$.

${ }^{12}$ Letter from Home Secretary to Archbishop of the West Indies, 17 January 1955, TF3716, USPG archives.

${ }^{13}$ Letter from Home Secretary to Archbishop of the West Indies, 15 January 1955, TF3716, USPG archives.

${ }^{14}$ There is correspondence to suggest that after the trip the SPG did want to sit down with the photographer and make a fuller record of the locations where the images were made, but there is no evidence that this happened. TF3716, USPG archives.

${ }^{15}$ Letter from Bryan Heseltine to Home Secretary, 19 February 1955, TF3716, USPG archives.

${ }^{16}$ Those familiar with the politics of immigration in the United Kingdom may be interested to know there is an extended discussion of the attraction of West Indian migrants to the 'Eldorado of the English Welfare State' (Dewi Morgan, Foreword, in Roberts 1955, 15).

${ }^{17}$ From the perspective of the present it seems difficult to reconcile the signal sent by the choice of Lennox Boyd to open this exhibition with the very outspoken stance on apartheid expressed in the South Africa exhibition the previous year, placing the SPG simultaneously on the right and wrong sides of history, though undoubtedly such distinctions were rather less clear at the time.

18 'West Indies Exhibition: Scripting as Heseltine envisages it', File TF3715, USPG archives. There are discrepancies between the notes in the archive and photographs of the exhibition, suggesting that some decisions and alterations were made during the installation.

${ }^{19}$ The SPG's analysis of the region appears to have been informed by Thomas Simey, Professor of Social Science at the University of Liverpool.

${ }^{20}$ Sluga is talking particularly about Julian Huxley's shaping of UNESCO's early vision, though the point has a more general applicability, as this exhibition demonstrates.

${ }^{21}$ Letter from Home Secretary to Archbishop of the West Indies, 17 January 1955, TF3716, USPG archives.

${ }^{22}$ The archive is in fact three separate collections. The negatives and exhibition prints have been lost or discarded, leaving only contact prints. The latter are held in the Bodleian Library, the USPG archive, and in the photographer's personal collection, currently with the author. I have not been able to do the systematic work that would be required to identify the differences or overlaps between these collections (though some of the Bodleian's single contact images may have been cut from contacts sheets retained in the USPG archive, where numerous sheets have individual frames missing), or 
whether Heseltine retained any photographs for his own collection without submitting them to the SPG when he completed the commission.

${ }^{23}$ This same Raleigh advertisement appears to have also been used in southern Africa (Burke 2002, 512). 